\title{
O MUSEU COMO SISTEMA ABERTO TRÊS REFLEXÕES
}

\begin{abstract}
Arménio Rego*
O desafio intelectual para o Director é clarificar as bases teóricas e filosóficas do Museu e construir uma estrutura de gestão que permita a prestação de serviços consistentes com os objectivos da organização e relevantes para as necessidades do público.
\end{abstract}

Thompson, 1992

Muitos museus revelam uma aparência demasiado "cinzenta", snob e «sisuda». Fechados sobre si próprios, cultivam a erudição no pior sentido que o termo também comporta e esquecem as múltiplas variáveis e entidades que sobre eles (e deles) recebem influência. Ignoram que prestam serviços a públicos com diferentes necessidades, e que, como tal, devem usar estratégias diferenciadas para esses diversos segmentos do seu «mercado». Menosprezam o facto de, como prestadores de serviços (culturais, de lazer, de investigação, de entretenimento...), concorrerem com outras entidades, as quais lhes disputam os mesmos tipos de "clientes».

Urge transformar estas instituições em sistemas abertos, que não vejam nessa heterogeneidade uma ameaça, mas sim uma oportunidade para promoverem o desenvolvimento cultural das populações, a defesa da memória colectiva da comunidade em que se inserem, a ocupação dos tempos livres, a satisfação das necessidades de quem neles se revê e quer estudar/compreender.

* Docente da Universidade de Aveiro. 


\section{MUSEUS E GESTÃO}

A linguagem da gestão tem vindo a ser, progressivamente, adoptada em diversas actividades e instituições - sejam elas sociais, políticas ou culturais -, tradicionalmente dela arredias.

A adesão dos museus, enquanto organizações culturais, às perspectivas gestionárias constitui um reflexo particular dessa mesma adopção, conquanto se esteja, ainda, numa fase embrionária.

Tratando-se de organizações peculiares, tradicionalmente envolvidas numa aura de elitismo que as tem mantido afastadas de concepções culturais mais abrangentes, muitos museus comportam-se, em certa medida, como sistemas fechados, isto é, como instituições auto-centradas e fortemente alheadas do meio - que, ao fim e ao cabo, os fez nascer e os justifica.

Sejam as preocupações atinentes à exiguidade de financiamentos, sejam as tendências sociais que, progressivamente, têm vindo a valorizar o património histórico-cultural e a defesa da identidade cultural dos povos e comunidades, sejam as orientações políticas que pugnam pela importância da cultura (lato sensu) na ocupação dos tempos livres e na formação cívica dos cidadãos ... todas têm contribuído para que aos responsáveis pelos museus seja exigida uma postura de abertura e intercâmbio estreito com o meio circundante.

As reflexões que se seguem não são as de um expert em Museologia; resultam, tão-só, da tentativa (necessariamente modesta) de partilharmos alguns pontos de vista com aqueles que, por curiosidade ou necessidade, pretendem estabelecer o contacto com a Gestão e a sua adaptabilidade às organizações museológicas.

Procuraremos, num primeiro momento, fazendo uso de uma linguagem metafórica, expor dois modelos da organização-museu; posteriormente, apresentaremos três reflexões, assentes no paradigma do museu como sistema aberto.

\section{O MUSEU COMO SISTEMA ABERTO}

Embora simplisticamente, podem resumir-se a dois os paradigmas organizacionais da instituição museológica; cada museu concreto situa-se num ponto do contínuo que tem em cada extremidade esses dois modelos: o museu-relógio e o museu ser-vivo. 
Fig. 1

OS DOIS PARADIGMAS DA ORGANIZAÇÃO MUSEOLÓGICA

\begin{tabular}{|c|c|c|}
\hline O Museu-relógio é & $\begin{array}{l}\text { Museu-relógio } \\
\text { sistema fechado }\end{array}$ & $\begin{array}{c}\text { Museu ser-vivo } \\
\text { sistema aberto }\end{array}$ \\
\hline
\end{tabular}

ca, fechada, que fornece a mesma informação a um professor ou a um camponês, a um idoso ou a um aluno do $1^{\circ}$ ciclo, a um minhoto ou a um parisiense; se não estiver avariado, funciona sempre da mesma maneira; só se lhe vê a engrenagem se for aberto (e, enquanto aberto, deixa de cumprir a sua função); apenas lhe conhece o mecanismo o indivíduo erudito; se muito manipulado, corre o risco de avariar; para continuar a sua marcha pachorrenta, apenas necessita que a tutela lhe dê corda ou lhe introduza a energia financeira.

O Museu ser-vivo é uma organização dinâmica; para sobreviver, abre-se ao ambiente cultural, económico, social; adapta-se aos diferentes públicos que o procuram, visando conhecer-lhes as necessidades e satisfazê-las diferenciadamente; não é por lhe mexerem e lhe procurarem conhecer a engrenagem que avaria; pelo contrário, deixa de cumprir a sua função se não o manipularem; a corda e a energia financeira são obtidas da tutela mas, também, dos diferentes tipos de entidades que compõem o seu meio ambiente.

De pendor algo naïf, estas duas imagens são as de um outsider ao mundo da museologia, a quem resta olhar para o Museu como uma organização que presta serviços e que só pode cumprir a sua missão e sobreviver se se comportar como um sistema aberto.

Gerir um museu como um sistema aberto é semelhante - perdoe-se-nos a terminologia bélica - a enviar um míssil terra-ar em direcção a um avião; dado que o alvo se move, e porque as condições do percurso não são estáveis, a única possibilidade de o alcançar é obter, constantemente, informação acerca da sua posição e, em conformidade com esses dados, reorientar a direcção.

Um museu que não interage sistematicamente com o meio envolvente e que não obtém informações acerca da forma como está a alcançar os seus objectivos, não consegue reorientar o seu rumo e, assim, passa ao lado dos seus alvos. 
Fig. 2

O MUSEU COMO SISTEMA ABERTO QUE INTERAGE COM O AMBIENTE

\section{Inputs}

- Normas/legislação (europeia, da Unesco, portuguesa).

- Materiais p/restauro.

- Equipamentos (para exposição, para desumidificação ...).

- Informações (sobre os concorrentes, as notícias dos media, as reacções dos públicos, a vida política nacional e intemacional ...).

- Instruções da tutela.

- Dinheiro (mecenas, Estado, autarquias ...).

- Colaboradores (com as suas qualificações, a sua cultura, a sua motivação ...).

- Obras no edifício.

- Energia eléctrica.

- Peças/Colecções.

- Etc.

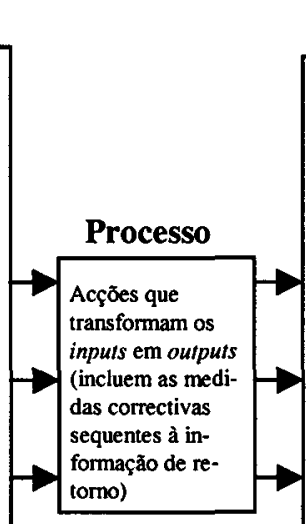

Outputs

- Exposiçōes.

- Publicidade.

- Obras conservadas; obras restauradas.

- Clientes satisfeitos (ou não).

- Colaboradores que saem.

- Informação para os media e para a comunidade.

- Brochuras/catálogos.

- Fugas de informação para os media.

- Protocolos com outras entidades.

- Edifício renovado.

- Informações à tutela.

- Greves.

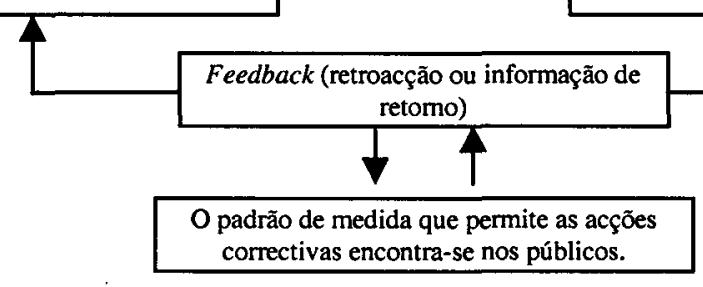

Serve este intróito para suscitar três reflexões:

1. o Museu vive inserido numa constelação de entidades $e$ variáveis que sobre ele exercem influência;

2. o Museu satisfaz necessidades dos seus públicos; como tais necessidades são diferenciadas, o modo de as satisfazer deve, também, ser distinto;

3. na satisfação dessas necessidades, o Museu concorre com outras entidades não museológicas. 


\section{AS ENTIDADES E VARIÁVEIS QUE ENVOLVEM UM MUSEU}

A primeira reflexão remete-nos para a ideia de que existem, em torno do Museu, múltiplas entidades (stakeholders, na linguagem técnica) com interesses da mais variada ordem (Fig. 3). O Museu pode perfilhá-los, satisfazê-los, combatê-los, repeli-los, servir-se deles para alcançar os seus objectivos... mas nunca ignorá-los, mesmo que admita que as exigências e pressões são ilegítimas.

Fig. 3

(ALGUMAS) ENTIDADES COM (EVENTUAIS) INTERESSES NO MUSEU

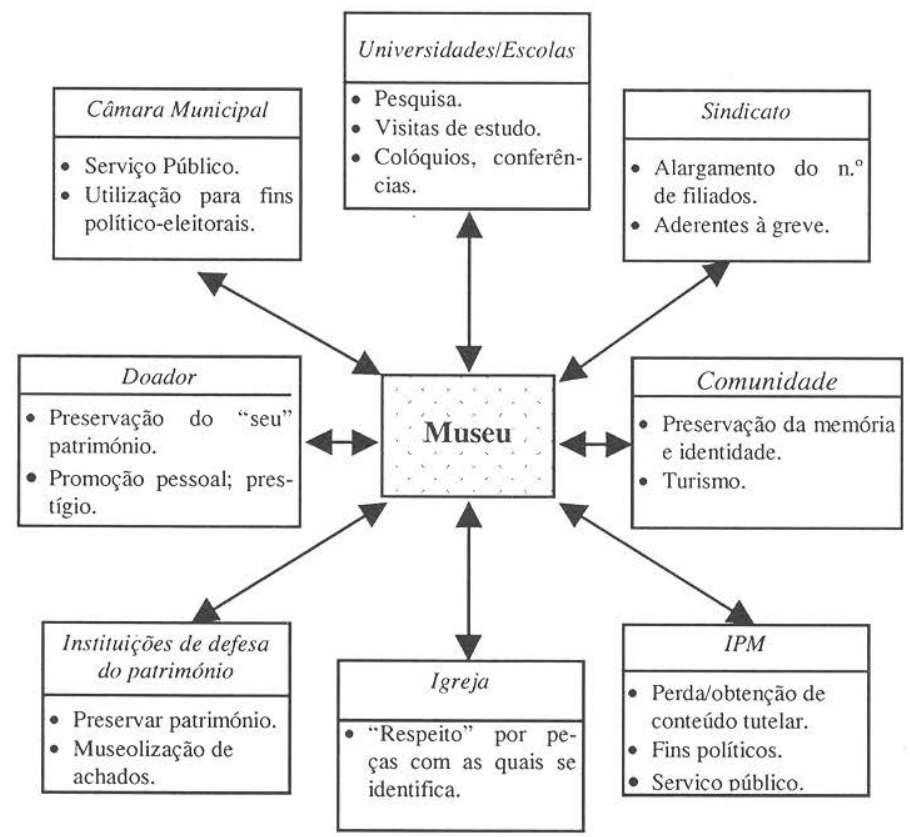




\section{Fig. 4}

(EXEMPLOS DE) VARIÁVEIS AMBIENTAIS PERTINENTES PARA A GESTÃO DOS MUSEUS

\begin{tabular}{|c|c|}
\hline Variáveis & Aspectos (eventualmente) pertinentes \\
\hline Demográficas & $\begin{array}{l}\text { - Meio rural versus meio urbano. } \\
\text { - Nível de habilitações da população. } \\
\text { - Estrutura etária (uma população idosa terá uma postura, face a um } \\
\text { museu, diferente da de uma população mais jovem....). }\end{array}$ \\
\hline Políticas & $\begin{array}{l}\text { - Estabilidade/instabilidade política. } \\
\text { - Eleições autárquicas. } \\
\text { - Sensibilidade dos diferentes partidos/governos/ministros às questões } \\
\text { museologicas. } \\
\text { - Rupturas políticas, com consequentes mudanças de nomes e encer- } \\
\text { ramentos de instituições... } \\
\text { - Políticas governamentais (OTL, cartão jovem...). } \\
\text { - Ideologia do regime. }\end{array}$ \\
\hline Ecologicas & $\begin{array}{l}\text { - Força das associações ambientalistas. } \\
\text { - A poluição afectando o edifício. }\end{array}$ \\
\hline Tecnológicas & $\begin{array}{l}\text { - Determinação da idade de uma peça. } \\
\text { - Técnicas de conservação e restauro. } \\
\text { - Transportes. } \\
\text { - Pesquisa da autenticidade. }\end{array}$ \\
\hline Económicas & $\begin{array}{l}\text { - Poder de compra do público. } \\
\text { - Grau de industrialização. } \\
\text { - Situação económico-financeira das empresas (potenciais mecenas). } \\
\text { - Distribuição da riqueza (ex.: se, apenas, uma pequeníssima parte da } \\
\text { população tem rendimentos «extra», os «clientes» potenciais dos mu- } \\
\text { seus serão reduzidos). } \\
\text { - Época de crise = menos receitas do orçamento do Estado. }\end{array}$ \\
\hline Socioculturais & $\begin{array}{l}\text { - Cultura do país/região. } \\
\text { - Religião. }\end{array}$ \\
\hline $\begin{array}{l}\text { Dimensão } \\
\text { internacional }\end{array}$ & $\begin{array}{l}\text { - As negociações entre Estado português e francês sobre as peças para } \\
\text { o Museu Vieira da Silva-Arpad Szenes foram afectadas pela mudança } \\
\text { do governo francês. } \\
\text { - Em clima de crise internacional, o transporte de obras de arte críticas } \\
\text { torna-se mais problemático. } \\
\text { - Europália. } \\
\text { - Financiamentos da União Europeia. }\end{array}$ \\
\hline
\end{tabular}


Idêntica reflexão pode ser lançada sobre as múltiplas variáveis que podem afectar o funcionamento de um Museu (Fig. 4). Gerir uma instituição museologica implica estar atento a todas elas, olhar em redor, descortinar alterações em domínios afastados da vida quotidiana da instituição ... mas que, nela, podem vir a ter repercussões (directa ou indirectamente, de imediato ou a longo prazo).

\section{O MUSEU PERANTE AS NECESSIDADES DE PÚBLICOS DIFERENTES}

A segunda reflexão obriga-nos a olhar para o Museu como uma organização que satisfaz necessidades. Dado que os públicos são distintos entre si, as suas necessidades são, também, heterogéneas. Cabe ao Museu proceder a diferentes combinações das variáveis do Marketing-mix, atendendo às particularidades de cada tipo de público (sem nunca esquecer, todavia, que o que cada visitante consome é uma experiência sui generis, de que ninguém mais desfruta da mesma maneira). São sete essas variáveis, e costumam ser designadas por «Modelo dos 7 P's»:

Fig. 5

O MODELO DOS 7 P'S

\section{AS VARIÁ VEIS DO MARKETING-MIX DOS MUSEUS}

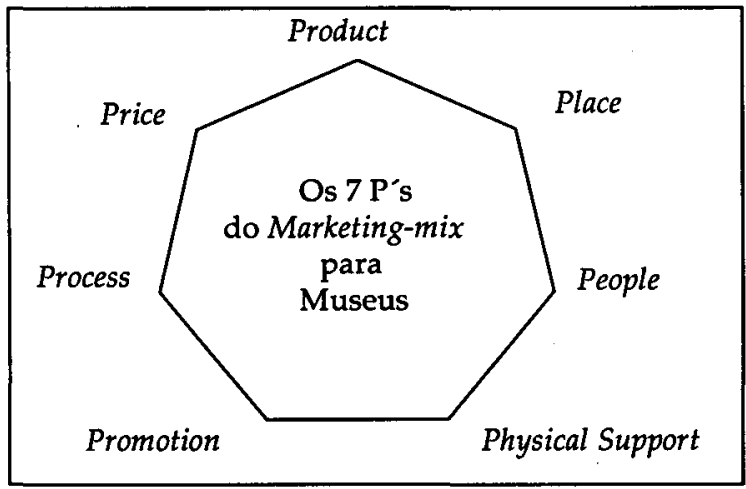

1. Product - que colecções apresentar? Como apresentá-las? O que podemos oferecer ao visitante? Uma oportunidade para se formar culturalmente? Uma refeição no bar? Uma oportunidade para se promover socialmente? Uma oportunidade para se divertir? Uma base para pesquisa? 
2. Price - de entrada, de catálogos, de cafetaria ...

3. Promotion - que patrocinadores podemos cativar? Como comunicar com os diferentes tipos de público? Em que jornais? Em que revistas? Em que rádios? Será melhor o "passa-palavra"? Ou o cartaz?

4. Place/Distribution - onde fazer a exposição? No «nosso» museu? Ou podemos/devemos fazer uma exposição itinerante? O edifício é acessível? Está bem sinalizado? Precisa de melhorias? Que imagem transmite a quem o vê?

5. People - que funcionários devem estar à disposição dos diferentes tipos de público? Que formação devem ter? Será necessária formação adicional em áreas específicas para fazer face às necessidades de um tipo particular de público?

6. Process - que mudanças a introduzir no processo que conduz à prestação do serviço, de modo a melhorar a qualidade da experiência vivida pelo visitante? Como conciliar a publicidade com aquilo que temos para oferecer?

7. Physical Support - a que aspectos tangíveis podemos recorrer para criar uma imagem do serviço (que é, por natureza, intangível)? O bar será importante? E que espaços podemos proporcionar para as pessoas desfrutarem?

$\mathrm{O}$ tratamento indiferenciado dos públicos tem como consequências a incapacidade de comunicar com vários deles, a insatisfação de alguns com o serviço prestado, o desaproveitamento do potencial de formação cultural que o Museu encerra, etc. Da mesma forma que as empresas segmentam o seu mercado de modo a fornecer a cada segmento uma combinação específica de variáveis do Marketing-mix, assim também um Museu necessita de identificar os seus diferentes tipos de público, de modo a satisfazer diferenciadamente as necessidades específicas de cada um (fig. 6). 
Fig. 6

DIFERENTES ESTRATÉGIAS DE MARKETING-MIX PARA DIVERSOS PÚBLICOS

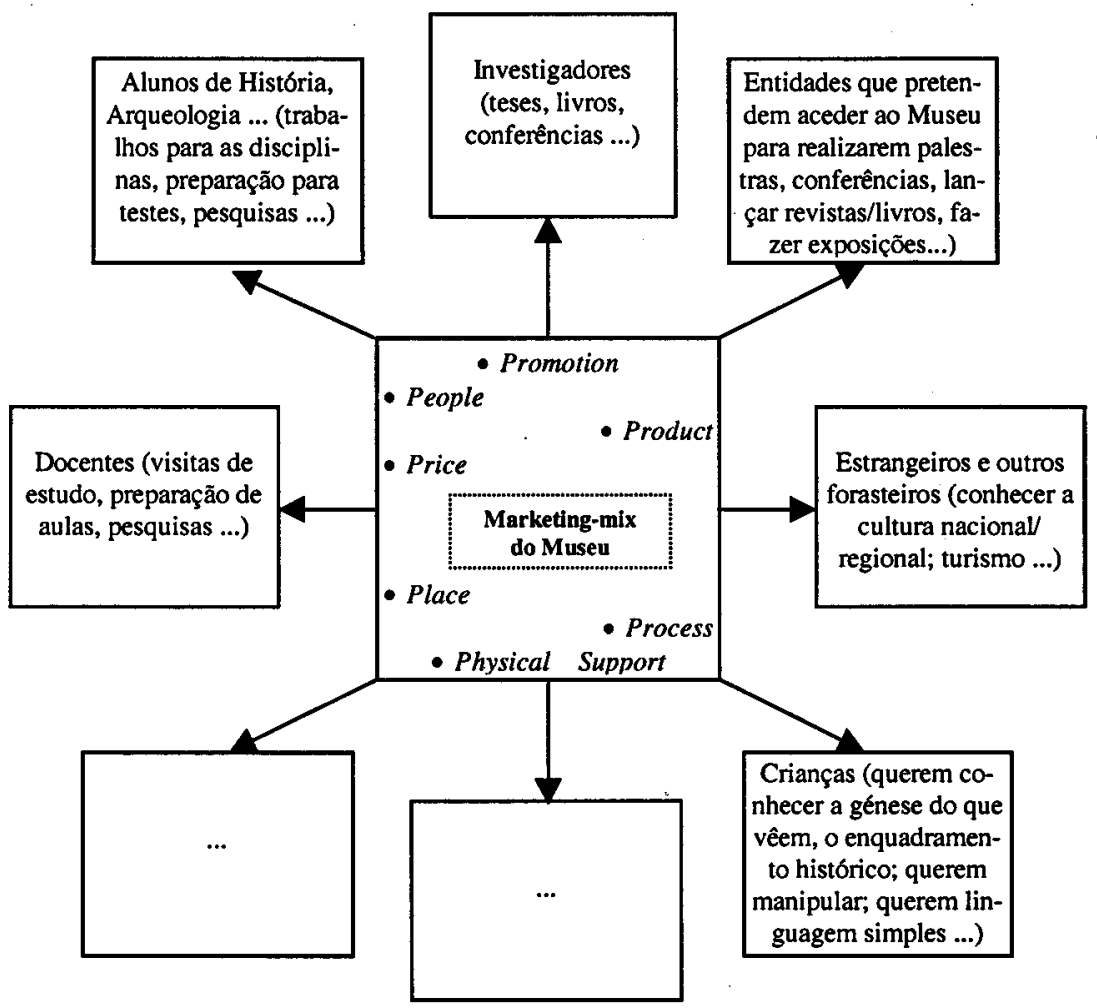

\section{OS CONCORRENTES DO MUSEU}

A terceira reflexão debruça-se sobre uma espécie de miopia que advém de se ver os outros museus como os únicos concorrentes do «nosso» Museu. Se é certo que os concorrentes de uma pizzaria não são, apenas, as outras pizzarias (são-no todos os restaurantes), se é verdade que a CP tem como concorrentes todas aquelas empresas que satisfazem a mesma necessidade (transporte), também é necessário admitir que as galerias de arte, os cinemas, os teatros ... concorrem com o Museu na satisfação das necessidades dos diferentes públicos. Isto sucede porque os diferentes serviços proporcionados pelas diferentes organizações são substitutos entre si, isto é, satisfazem as mesmas (ou similares) necessidades. 
Significa isto, também, que o potencial que o Museu detém é, muitas vezes, superior ao que tradicionalmente lhe é atribuído.

Fig. 7

OS CONCORRENTES POTENCIAIS DO MUSEU

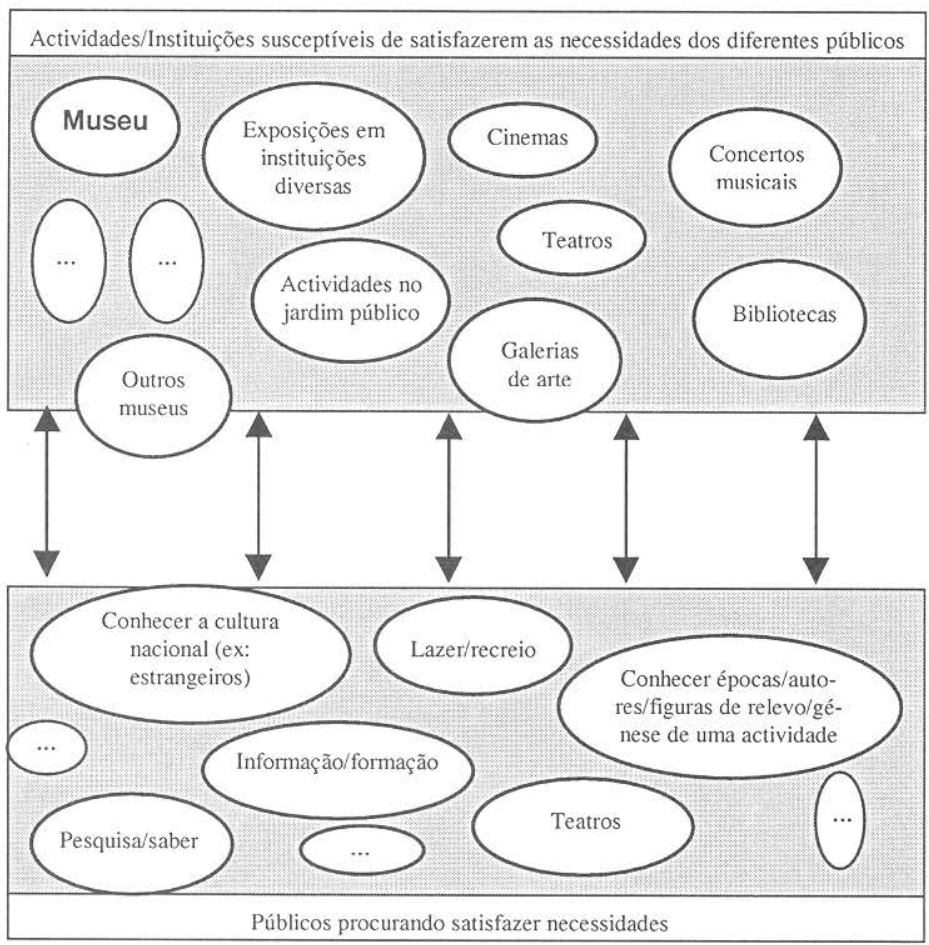

\section{CONCLUSÃO}

Em suma, o Museu tem que funcionar como um sistema aberto. Isso implica:

- estar atento ao meio envolvente;

- ser suficientemente perspicaz para dele aproveitar oportunidades (uma empresa que necessita de se promover; uma organização ecológica que defende o mesmo interesse que o Museu; uma escola que pretende fazer uma visita de estudo; uma comunidade estudantil pouco informada das potencialidades do museu ...) e ultrapassar constrangimentos (de financiamento, por exemplo); 
- estar ciente de que não pode funcionar como mero armazém de peças, de colecções ...;

- estar vocacionado para servir de modo diferenciado as múltiplas necessidades de um público heterogéneo.

Só assim poderá tornar-se um ente vivo, promovendo o desenvolvimento cultural das populações, protagonizando a defesa da memória colectiva da comunidade em que se insere, incentivando essa mesma comunidade a preservar a sua identidade.

\section{BIBLIOGRAFIA}

BERTALANFFY, Ludwig von (1973), Théorie Générale des Systèmes, Paris, Dunod.

BRADFORD, Hugh (1994). «A New Framework for Museum Marketing», in Kevin Moore (ed.), Museum Management, London, Routledge.

BROOKES, Bill (1992), «Asking the Public what they want», in John Durant (ed.) Museums and the Public Understanding of Science, London, Science Museum.

DRUCKER, Peter (1993), Organizações sem Fins Lucrativos (trad. do inglês), Libsboa, 1993, Difusão Cultural.

EDGETT, Scott e PARKINSON, Stephen (1993), «Marketing for Service Industries», The Service Industries Journal, vol. 13, n. ${ }^{\circ} 3$.

LENDREVIE, Jacques et al. (1992), Mercator. Teoria e Prática do Marketing, Lisboa, Publicações Dom Quixote.

MCLEAN, Fiona (1994), «Services Marketing. The Case of Museums», The Service Industries Journal, vol. $14, \mathrm{n}^{\circ} 2$.

MILES, Roger e TOUT, Alan (1992). «Exhibitions and the Public Understanding of Science», in John Durant (ed.), Museums and the Public Understanding of Science, London, Science Museum.

PAYNE, Adrian (1993), The Essence of Services Marketing, Englewood Cliffs, N. J., Prentice Hall.

PITT, Leyland e JEANTROUT, Barbara (1994), «Management of Customer Expectations in Service Firms. A Study and a Checklist», The Service Industries Journal, vol. 14, n. ${ }^{\circ} 2$.

REICHELD, Frederick F. (1996), «Learning from Customer Defections», Harvard Business Review, March-April.

THOMPSON, John (1992), «The role of the director», in John Thompson (ed.), Manual of Curatorship, $2^{\text {nd }}$ ed., Butterworth. 